\title{
EDITORIAL
}

\section{Guidelines and risk factor management}

\section{P Primatesta}

Heart 2005;91:417-418. doi: 10.1136/hrt.2004.048058

\section{Efforts to reduce the death rate from cardiovascular disease in the UK are beginning to make a difference}

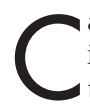
ardiovascular disease (CVD) has been identified as one of the leading contributors to the global disease burden. In the UK it is the main cause of death, although death rates for CVD have been falling since the latter part of the 20th century. The government white paper Saving lives: our healthier nation, published in 1999, recognised that the UK is one of the worst countries for deaths from circulatory disease, and identified heart disease and stroke as among the four priority areas to tackle. ${ }^{1}$ The target was set of reducing the death rate from coronary heart disease (CHD) and stroke among people aged under 75 years by at least two fifths, to 83.8 deaths per 100000 population by the year 2010, a target that looks set to be achieved.

The National Service Framework (NSF) for CHD set the agenda in the year 2000 for the modernisation of CHD services over a 10 year period. ${ }^{2}$ Twelve service standards for improved prevention, diagnosis, treatment, and rehabilitation, and goals to secure fair access to high quality services, were set. A recently published progress report showed that considerable progress has already been made in some areas. ${ }^{3}$

Instead of concentrating solely on risk factors in isolation, greater attention is now paid to a broader consideration of the CVD risk of individuals, aiming at reducing their total CVD risk through appropriate interventions. ${ }^{4-6}$ Multifactorial interventions have been advocated to address their risk. This is what both national and international guidelines refer to, by tailoring prevention and management of the disease to the individual's risk and encouraging general practitioners (GPs) to "negotiate" the best strategy with each individual patient. ${ }^{7}$

\section{GENERAL PRACTICE AUDITS}

In this issue of Heart two studies investigate the effect of guidelines on the management of risk factors for CVD. Martin and colleagues ${ }^{8}$ compare $^{2}$ the results of two audits in general practice in Lothian. A first audit was carried out to assess CVD secondary prevention in patients who had undergone coronary artery bypass graft surgery (CABG) between 1988 and 1997. This was followed by interventions to improve the care of these patients in general practice (notification of $\mathrm{CABG}$, support towards implementation of local guidelines). Subsequently a second audit included a further sample of the initial group of patients and a sample of those whose operations were between 1998 and 1999. Some of the results were encouraging: management of hypertension and dyslipidaemia improved between the two audits, with more people detected, treated and controlled. Use of aspirin, high in both audits, improved further in the latter. However, when comparing the patients whose general practices were included in the audit project with "usual care", systolic blood pressure was lower (and below target) and total cholesterol lower in those practices that had taken part in the audit project than in the control group. Also, awareness and treatment of hypertension and hypercholesterolaemia may have improved, but their control was still inadequate, and a large proportion of patients with CABG (30\%) were not receiving treatment with a statin (no information was available on lifestyle modification). The authors conclude that the improvement in blood pressure and cholesterol management was due in large part to the collaboration between primary and secondary care, with notification to GPs of patients who had CABG and would benefit from secondary prevention, and support from the Lothian General Practice Audit Committee.

\section{HEART DISEASE PREVENTION IN DIABETICS}

Another study in this issue, by Emberson and colleagues, ${ }^{9}$ examines a cohort of older British people from the British regional heart study and the British women's heart and health study, comparing primary and secondary coronary heart disease prevention between diabetics and non-diabetics. In primary prevention, diabetics were more likely to receive aspirin, statins, and antihypertensive drugs than non-diabetics, although higher treatment rates were not reflected in better control of hypertension and the lower levels of cholesterol observed among diabetics were not attributable to treatment with statins. In secondary prevention things were no better, with no differences in treatment between diabetics and non-diabetics (and low levels overall). Hence the overall primary and secondary CHD prevention in this high risk group was very low.

Both studies point out that improvements in the management of risk factors for CVD are slow and far from ideal.

Is it unrealistic to expect clinical practice to achieve those targets set in the guidelines? It has been shown that both at the national ${ }^{10}$ and international ${ }^{11}$ level even quite simple evidence is difficult to implement. Should we therefore,

Abbreviations: $C A B G$, coronary artery bypass graft surgery; CHD, coronary heart disease; CVD, cardiovascular disease; GP, general practitioner; NSF, National Service Framework 
admitting our failures, stop pursuing those targets and accept that clinical practice is different from the "ideal world" of clinical trials?

\section{CVD MORTALITY RATES DOWN}

Surely the fact that mortality rates for CVD are coming down at a rate of about $6.5 \%$ annually in England from the mid 1990s indicates that the concerted efforts are paying some dividends, and setting targets focuses the minds of health professionals. It is true to say that several factors influence risk factor management and may impede the achievement of the targets set in the guidelines. For example, differences in mortality by social class are still evident. It may be that many people from socioeconomically deprived backgrounds find it difficult to change their lifestyle, and are less articulate in discussing the management of their disease with healthcare professionals. Diabetics are another group of people who need strict monitoring. Given the high CHD event rates among patients with diabetes and the high case fatality rates among diabetic subjects who suffer an acute myocardial infarction, ${ }^{12}$ and the benefits shown by clinical trials on the control of blood pressure, ${ }^{13}$ lipids, ${ }^{14}$ and management of lifestyle, more stringent targets have been set for diabetic patients. ${ }^{4}$ However, it has been demonstrated that these patients are less amenable to complying with medication and lifestyle changes, ${ }^{15}$ and the results presented in this issue indicate that, especially among older people (who may per se present as a more difficult group to treat), this may still be the case. ${ }^{9}$ More and greater strategies to encourage these patients to attend and engage are needed.

Can the performance of GPs be measured against achievement of targets? Guidelines cannot (and should not) replace clinical judgement, but as the word implies they should give general advice and guidance, based on best evidence. They are not set in stone, and when the evidence changes revisions may become necessary. On the other hand revision of targets on the basis of new evidence may result in stricter guidelines, which may in part account for the continuous pursuit of optimal management without ever reaching it.

The new General Medical Services contract requires GPs to step up their efforts in the diagnosis and management of chronic disease; it offers financial incentives by means of points collected through achievement of quality markers. ${ }^{16}$ In relation to patients with CVD, measuring and managing blood pressure, cholesterol, and smoking would equate to a total of 242 clinical points, $44 \%$ of the total points available. How can the targets relating to the management of these risk factors be met? Interventions such as support in management of disease and implementation of local guidelines may offer a good level of backing to GPs, and close links with secondary care services are also necessary, as Martin and colleagues ${ }^{8}$ demonstrated. In the management of CVD risk, as with most things, the pursuit of perfection is itself pointless, but this should not discourage the pursuit of excellence.

\section{REFERENCES}

1 Department of Health. Saving lives: our healthier nation. London: The Stationery Office, 1999.

2 Department of Health. National service framework for coronary heart disease. Modern standards and service models. 2000. London: The Stationery Office, 2000.

3 Department of Health. National service framework for coronary heart disease. Delivering better heart services. Progress report 2003. London: The Stationery Office, 2003.

4 Williams B, Poulter NR, Brown MJ, et al. Guidelines for management of hypertension: report of the fourth working party of the British Hypertension Society, 2004-BHS IV. J Hum Hypertens 2004; 18:139-85.

5 NICE. Hypertension - Management of hypertension in adults in primary care. Clinical guideline 18. London: National Institute for Clinical Excellence, 2004.

6 NICE. Management of type 2 diabetes: management of blood pressure and blood lipids. Clinical guideline $\mathrm{H}$. London: National Institute for Clinical Excellence, 2002.

7 De Backer G, Ambrosioni E, Borch-Johnsen K, et al. European guidelines on cardiovascular prevention in clinical practice: third joint task force of European and other societies on cardiovascular disease prevention in clinical practice. Eur Heart J 2003;24:1601-10.

8 Martin TM, Irving JR, Sutherland $M$, et al. Improving secondary prevention in coronary bypass patients: closing the audit loop. Heart 2005;91:456-9.

9 Emberson JR, Whincup PH, Lawlor DA, et al. Coronary heart disease prevention in clinical practice: are patients with diabetes special? Evidence from two studies of older men and women. Heart 2005:91:451-5.

10 Primatesta $\mathbf{P}$, Brookes $M$, Poulter NR. Improved hypertension management and control: result from the Health Survey for England. Hypertension $2001 ; 38: 827-32$

11 EUROASPIRE I and II Group. Clinical reality of coronary prevention guidelines: a comparison of EUROASPIRE I and II in nine countries. Lancet 2001;357:995-1001.

12 Haffner SM, Lehto S, Ronnemaa T, et al. Mortality from coronary heart disease in subjects with type 2 diabetes and in non-diabetic subjects with and without prior myocardial infarction. N EngL J Med 1998;339:229-34.

13 Hansson L, Zanchetti A, Carruthers SG, et al. Effects of intensive bloodpressure lowering and low-dose aspirin in patients with hypertension: principal results of the hypertension optimal treatment (HOT) randomised trial. Lancet 1998;351:1755-62.

14 Heart Protection Study Collaborative Group. MRC/BHF heart protection study of cholesterol-lowering with simvastatin in 5963 people with diabetes: a randomised placebo-controlled trial. Lancet 2003;361:2005-16.

15 Toobert DJ, Hampson SE, Glasgow RE. The summary of diabetes self-care activity measure: results from 7 studies and a revised scale. Diab Care 2000;23:943-50.

16 Department of Health. Delivering investment in general practice: implementing the new GMS contract. London, 2003.

\section{ELECTRONIC PAGES}

\section{Heart Online case reports: www.heartjnl.com}

$\mathrm{T}$

he following electronic only articles are published in conjunction with this issue of Heart.

\section{Aborted myocardial infarction: a clinical-magnetic resonance correlation}

\section{G Tarantini, A Ramondo, S Iliceto}

This report illustrates a magnetic resonance image of aborted myocardial infarction after primary angioplasty. Myocardial oedema in the absence of late enhancement seems to be the magnetic resonance marker of the myocardium at risk of infarction that has been reperfused within 30 minutes and aborted in the clinic.

(Heart 2005;91:e24) www.heartjnl.com/cgi/content/full/9l/ $4 / \mathrm{e} 24$
Ebstein's malformation with atrial septal defect, right cor triatriatum, and right overt accessory atrioventricular pathway R-X Wang, X-R Li, D-J Qian

A 31 year old man was admitted to hospital for abrupt syncope. Two dimensional echocardiogram in the apical four chamber view showed Ebstein's malformation. This is the first documented case of Ebstein's malformation with atrial septal defect, right cor triatriatum, and a right overt accessory atrioventricular pathway.

(Heart 2005;91:e25) www.heartjnl.com/cgi/content/full/91/ $4 / \mathrm{e} 25$ 